Open Access

\title{
Students as co-creators of technology-rich learning activities in higher education
}

\author{
Begoña Gros ${ }^{*}$ and Marta López
}

\author{
* Correspondence: bgros@ub.edu; \\ Martalc88@gmail.com \\ Department of Teoria i historia de \\ l'educació, Universitat de Barcelona, \\ Passeig de la Vall d'Hebron,171, \\ 08035 Barcelona, Spain
}

\begin{abstract}
This article describes an ongoing study that, ultimately, aims to help students become co-creators of their courses. It discusses methodologies to support student empowerment and engagement.

It uses the Learner Centric Ecology of Resources perspective (Luckin 2006) to explore the experiences of teachers and students from two different universities as they participated in co-design processes for selecting digital resources during the design of the courses.

The data presented in the study was collected during the design workshops with the participation of teachers and students. The Ecology of Resources Design Framework was identified by the participants as a good facilitator during the co-design process. However, time seems to be a critical factor. A sustained dialogue over time is required to generate the context of trust needed between students and teachers and to explore the different levels of expertise.
\end{abstract}

Keywords: Co-design, Higher education, Technology-rich learning, Learning scenarios, Ecology of resources

\section{Introduction}

Researchers claim that it is essential for educational systems to establish a dialogue between learners and educators about educational reform, as a vital requirement for developing new mediation tools and practices either in the school (Clark, Logan, Luckin, Mee, \& Oliver, 2009) or university context (Conole, Creanor, Irving, \& Paluch, 2007). In higher education, students can take an important role in providing information about how learning should take place and which technologies and learning environments best meet their needs. However, the opportunities to contribute as partners to the design of learning scenarios are very scarce (Bovill, Cook-Sather, \& Felten, 2011). While the literature is rich in case studies of children participating in the design of technology products, it is nevertheless limited when it comes to the critical design perspective of undergraduate students. There are few studies that focus on exposing their thoughts and desires from a design perspective (Palaigeorgiou, Triantafyllakos, \& Tsinakos, 2011). However, "powerful learning begins to manifest when students take responsibility and ownership for their learning when they become co-creators of their learning experience, rather than their education being something that is done to them. True student empowerment and engagement begins when we cross the threshold of co-creation" (Wright, 2012).

(c) 2016 The Author(s). Open Access This article is distributed under the terms of the Creative Commons Attribution 4.0 International License (http://creativecommons.org/licenses/by/4.0/), which permits unrestricted use, distribution, and reproduction in any medium, provided you give appropriate credit to the original author(s) and the source, provide a link to the Creative Commons license, and indicate if changes were made. 
According to Seale (2009) there is an implicit assumption that students' feedback will have a transformative impact on teaching practices and curriculum development. However, it is necessary to create a framework to connect theory and practice from which to articulate the implementation of concrete actions so that the "student voice" can really have an impact on universities. According to this author, participatory methods have this potential and are the most appropriate. Similarly, Sanoff (2007) considers that participatory design is an attitude for change and can promote student engagement. Healey (2014) points out that there are many different areas to which students can contribute as co-designers: learning, teaching and assessment; subject-based research and inquiry; scholarship of teaching and learning; and curriculum design, pedagogical advice and consultancy.

The present article describes an exploratory study that uses the Learner Centric Ecology of Resources model (Luckin, 2008) to support the design of technology-rich learning activities. We focused the students' participation on the design of courses, adopting an inquiry-based learning model supported by technology. The study has two main goals: 1) to analyse how the Learner Centric Ecology of Resources model was used to support the selection of the resources using a co-design methodology, and, 2) to analyse the contribution of the students to a co-design process to build a learning environment supported by ICT.

In the following sections we describe the Learner Centric Ecology of Resources (Luckin, 2008) as a model that we have used to support the co-design processes for selecting digital learning resources. Next, we present the methodology of the study and we describe the main results. Finally, we discuss the opportunities and problems observed so far in the experiences of students as co-designers of the learning scenarios using digital resources and the use of the Learner Centric Ecology of Resources model.

\section{The ecology of resources design framework}

The Learner Centric Ecology of Resources developed by Luckin (2008) is based on Vygotsky's sociocultural theory. Vygotsky's theory suggests that development depends on interaction with people and the tools that the culture provides to help form their own view of the world. Traditionally, psychological functions (attention, memory, cognition, etc.) were considered part of the individual mind. Vygotsky changed the conception of individuality, considering that the psychological functions are distributed in a community of learners and emphasizing a contextualized and social approach. To elaborate the social dimension of psychological functioning, Vygotsky developed his well-known notion of the Zone of Proximal Development (ZPD), which he defined as "the distance between the actual developmental level as determined by independent problem solving and the level of potential development as determined through problem solving under adult guidance, or in collaboration with more capable peers" (Vygotsky, 1978, p. 86). Learning should take place in the learner's ZPD. The support and guidance provided for learners facilitate internalization of the knowledge needed to complete the task. Based on this idea, Bruner (Wood, Bruner, \& Ross, 1976) introduced the concept of scaffolding, which refers to the support given to facilitate learning. "Successful scaffolding requires collaboration or assistance for a learner or group of learners from teachers or other more able partners who must provide appropriately challenging activities accompanied by the right quantity and quality of assistance" (Luckin \& Du Boulay, 1999, p.198). 
Luckin (2008) broadens the notion of the ZPD by more carefully considering the shared resources available in a context where knowledge is distributed. Luckin (2008, p. 450) considers that "the proliferation of ubiquitous and pervasive technologies requires that we now look beyond scaffolding within software and the resources that it might make available to teachers and learners". In order to try to clarify the relationship between the ZPD and educational technology, Luckin (2006) introduces two new notions: the Zone of Available Assistance (ZAA) and the Zone of Proximal Adjustment (ZPA).

The ZAA describes the types of resources, both human and artefact, that are available within a particular context to help a more able partner offer appropriate assistance to a less able learner. The more able individual, in addition to being a resource, must ensure that the resources within the specific context are "organized and activated appropriately for that learner to form a ZPA" (Luckin, 2008, p. 451). The Zone of Proximal Adjustment (ZPA) represents a selected subset of the ZAA that includes the resources that are the most appropriate form of assistance for a given learner at a particular moment in time. The existence of a rich set of resources within the ZAA is not sufficient to ensure the interactions necessary to create a ZPD for the learner.

Based on this approach, The Ecology of Resources Design Framework aims to support the identification of the forms of assistance available to a learner that make up the resource elements with which that learner interacts. The Ecology of Resources model could be viewed as a set of elements that describe a learner's ZAA. However, the model can also be viewed as a dynamic process of instigating and maintaining learning interactions in technology-rich environments.

The Ecology of Resources Design Framework (Luckin, 2010) offers a structured process based on the Ecology of Resources model of context, through which educators and technologists can develop technologies and technology-rich learning activities that take a learner's wider context into account. The process is divided into three phases:

1. Create an Ecology of Resources model to identify and organize the potential forms of assistance that can act as resources for learning.

2. Identify the relationships within and between the resources produced in phase 1 . Identify the extent to which these relationships meet learner's needs and how they might be optimized with respect to that learner.

3. Develop the scaffolds and adjustments to support learning and enable the negotiation of a ZPA for learners. This support might, for example, be offered through the manner in which technology is introduced, used or designed.

\section{Methodology}

We conducted an exploratory study to analyse the use of the Ecology of Resources Design Framework to support the design of technology-rich learning activities with the participation of teachers and students. Our research questions are:

- Is the Learner Centric Ecology of Resources model useful to support the selection of the resources using a co-design methodology?

- How are students influenced by participating in a co-design process to build a learning environment supported by ICT? 
The study was developed in two universities where students are used to using technology, but which deploy different teaching models: online (Open University of Catalonia, UOC) and blended (University of Barcelona, UB).

A total of six teachers participated (four teachers from the University of Barcelona, and two from the Open University of Catalonia), and four courses were selected from different disciplinary areas: biomedical engineering, economics, tourism and communication. It was a convenience sample and participants were selected based on the following criteria: teachers with experience of using an inquiry-based learning approach from different faculties, who were also interested in improving student participation in the design of their courses (Fig. 1).

The co-design process takes place cyclically, through the following four main stages: exploration, envisioning, operationalization, and assessment and reflection. The first phase of the co-design process consisted of a series of participatory workshops with the six teachers from the four selected practice settings, along with members of the research team. These sessions served to introduce the participants to the dynamics of co-design and gain a deeper understanding of the contexts of practice. They were also orientated towards designing learning scenarios based on inquiry-based learning (IBL) and technology-enhanced learning (TEL) principles. In the second phase, a total of eleven students joined the design work groups with the aim of analysing the prototypes of the learning scenarios designed by teachers, bringing their own ideas and perspectives and thus validating the final designs. In the third phase, students were more deeply involved in the selection of digital resources and the Ecology of Resources Design Framework proposed by Luckin (2010) and described previously was applied.

In phase 1 , we asked the students to brainstorm digital resources that could support the learning scenario design for each course. To facilitate the activity, we provided a table in which they had to establish a distinction among digital resources used by the teachers, used by the students and the resources that should be used in the course. In phase 2, students identified the relationships within and between the resources described in phase 1 . In a workshop, the potential resources selected in phase 1 were analysed by the students and the results were discussed later with their teachers. The purpose of this phase was to identify the types of relationships that exist within and between the identified resources.

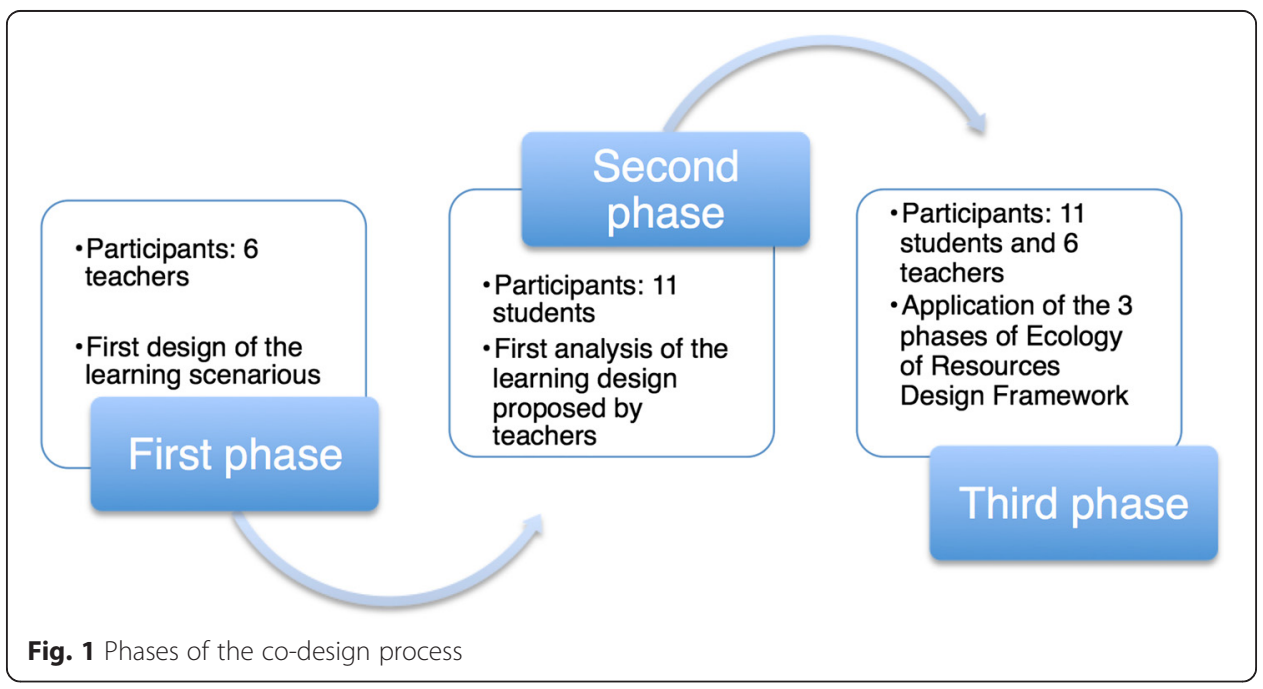


The identification of relationships and interactions between students, resources and filters is a key element in the design. These elements (relationships and interactions) must be optimized to meet students' learning needs (either through the use of technology or through other learning). In our case, this second phase focused on appropriate design principles for an inquiry-based learning model: ICT that supports participation, collaboration, planning and communication. Finally, in phase 3 the students and teachers analysed the scaffolds and adjustments to support learning and to enable the negotiation of a ZPA for learners. This support might, for example, be offered through the manner in which technology is introduced, used or designed.

During the three phases, data was collected using different instruments (Table 1) to thoroughly keep track of the co-design process:

1. Initial interviews with teachers and students in order to identify the main characteristics of the participants.

2. Participant observation and audio recordings of joint work sessions in phase 2 and 3.

3. Questionnaires addressed to both teachers and students after each work session.

\section{Results}

The results are described following the main findings explored in the different phases of the research: 1) an initial diagnosis of the characteristics of the participants; 2) description of the courses; 3) the results of applying the Learner Centric Ecology of Resources model; and 4) the students' perception during the co-design process.

\section{Characteristics of the participants}

Before starting the co-design process, we conducted individual interviews with teachers and students in order to identify the main characteristics of the participants. Interviews with teachers were conducted face-to-face and we used Skype for the interviews of the students.

The two professors at the UOC each had over 12 years' teaching experience and had spent over seven years teaching online educational courses. In the case of the UB, the

Table 1 Research instruments

\begin{tabular}{|c|c|c|}
\hline Instrument & Goals & Application \\
\hline Interview & $\begin{array}{l}\text { - Collect students' expectations about the } \\
\text { project and its contribution } \\
\text { - Measure the initial level of knowledge about } \\
\text { co-design processes. }\end{array}$ & $\begin{array}{l}\text { All students are individually interviewed, either } \\
\text { face2face or through Skype. }\end{array}$ \\
\hline Observation & $\begin{array}{l}\text { - To collect the discussion and work within } \\
\text { each working group to express the three } \\
\text { phases of the Learner Centric Ecology of } \\
\text { Resources model }\end{array}$ & $\begin{array}{l}\text { During the sessions of co-design (teachers and } \\
\text { students) }\end{array}$ \\
\hline Questionnaire & $\begin{array}{l}\text { - To collect evidence based on behaviours } \\
\text { and situations within each working group to } \\
\text { express: a) the degree of understanding of } \\
\text { the concepts, tools and procedures worked; } \\
\text { b) the type of use and productivity of the } \\
\text { procedures and instruments of representation } \\
\text { and co-design support proposed; c) the joint } \\
\text { dynamics of co-design (roles, interventions, } \\
\text { conflicts, key issues, phases). }\end{array}$ & $\begin{array}{l}\text { All students fill in a digital questionnaire (with } \\
\text { mostly open questions) when their } \\
\text { participation in the project has finished. }\end{array}$ \\
\hline
\end{tabular}


four teachers each had over 20 years' experience as university teachers. The six teachers were keen to introduce changes into their courses, mainly to increase student participation and motivation.

The two professors at the UOC considered that they had the necessary skills to incorporate digital technologies into teaching. The two professors of biomedical engineering claimed to have average experience, while the two economics teachers felt that they had little experience. The use of ICT in the courses was diverse. However, in all cases the virtual campus was used to provide students with information. The communication teacher used more applications for communication among students: videochat, Skype, and so on. However, all the teachers considered that the use of technology was mainly limited to the virtual campus (a Moodle platform) and that it was a challenge to use technology to support self-reflection, collaboration and communication.

A total of 11 students participated in the co-design process, nine of them from the UB and three from the UOC. Participation in the project was voluntary, none of the students had participated previously in a co-design process. The main difference between these two groups is age: the students were aged 19-22 in the case of UB, and 50, 41 and 36 in the case of the UOC. The reason is that the students at the online university (UOC) were part-time workers.

Regarding students' previous experience using technology as a learning support, the LMS was highlighted as the leading digital tool by most of them. However, the students pointed out other tools that they tend to use to work along with their peers like Dropbox, Google Drive, Facebook, WhatsApp and mobile devices.

\section{Characteristics of the courses}

The methodology used by the teachers before starting the co-design process was different in each course, but in all cases they considered that they were using an approach based on inquiry-learning design.

The tourism course was an online course. Students displayed a self-learning method based on continuous assessment and guided by tracking in the classroom. The principle of the course was to design a case study for students to work on, based on a real personal experience. The research results would be shared with each student in the classroom at various times. Initially, information sources were shared in a collective repository and thematic working groups were created related to the case studies discussed.

The communication course was also online, and was intended to resolve students' difficulties with moving to the dynamics of the final project that they had to develop to obtain their degree. Students worked in teams to develop projects while also conducting personal research. This course went from a model centred on the teacher-student relationship to a type of network organization, where students and teachers acted as a team sharing responsibilities for tasks and organizing and managing work processes.

The aim of the biomedical engineering course was to obtain clinical information exchange between heterogeneous systems of healthcare information. The teachers designed the course in two phases. In the first, students were distributed into different groups and each one was assigned a problem to analyse. In the second phase, the students were organized into new groups, composed of one member from each of the previous group. 
In the economics course different problematic elements were detected. Firstly, there was a significant gap in the students' reading comprehension, there was also a lack of competence in designing multimedia presentations in both the content and structure of graphical expression. The most remarkable environments involved in this problem relate to the increased work in virtual spaces, considered a positive factor, and therefore less work in the physical classroom.

The course design in the four cases was usually performed with the subject team, but none of the participants had previously participated in a process of co-design. However, all the teachers were interested in learning how to improve the design of their courses collaboratively and how to involve students in the design.

\section{The Learner Centric Ecology of Resources model}

We will now describe the results of the resources design phases proposed by Luckin (2010). In the first phase, students brainstormed digital resources to support the learning scenario. The aim was to analyse new ideas and tools and discover what students were used to using. We organized the tools into four sections according to their purpose: searching for information, organizing and managing content, creating and elaborating content, and sharing and collaborating.

Figure 2 shows that the categories in which students were most skilled at finding ICT tools were those used to search for information. The biomedical engineering students named the highest number of tools, for example, database software, Dropbox, videos and other specific software. Students from the UOC had more difficulties finding tools for the different categories. They mentioned only Power Point, virtual campus, WhatsApp, Dropbox and Google Drive. There were some tools that all groups referred to: Google Drive, virtual campus and Dropbox.

The students and teachers worked together to make a list of digital tools for learning in order to see what tools the teacher recommended, what tools were used on the students' own initiative, and what tools were used for other reasons. We found

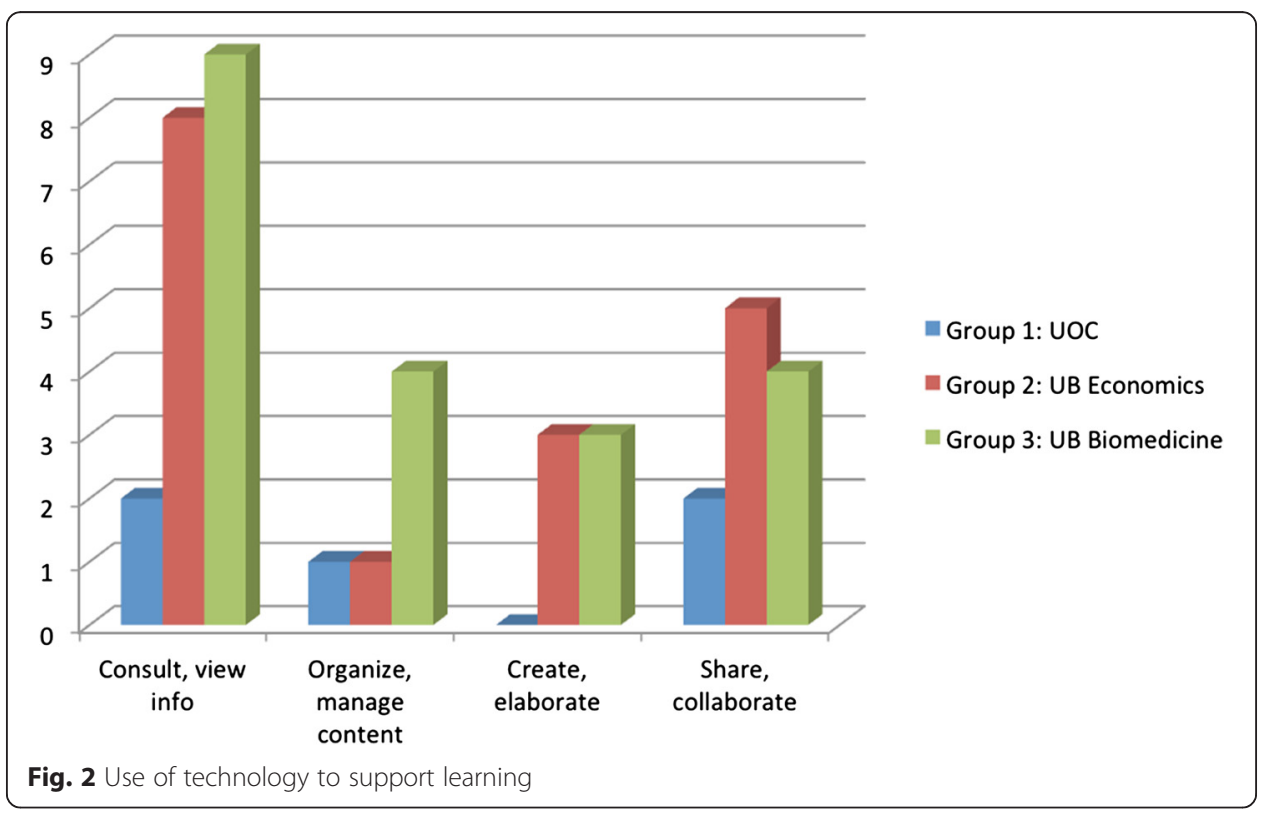


significant similarities between the UOC and UB groups of students. Databases, bibliographic managers and virtual campus were recommended by the teachers in both groups. Moreover, on their own initiative students used videos (such as Ted talks), Dropbox, Google Drive and WhatsApp. Students from the UOC contributed with other tools, such as digital libraries and the Wolfram Alpha program. The UB group contributed with Prezi, Skype and Adobe Connect. Finally, students from the UB considered that it could be useful for the learning scenarios to use social networks, mobile apps, Delicious, Pinterest and Google Drive. On the other hand, the UOC group mentioned Masterclass, Skype meetings and videoconferences.

The next step (and second phase) was to identify the extent to which these relationships met learners' needs. We asked the students why they used digital tools at university. In both cases (UB and UOC) students used these tools because their teachers recommended them. Less often, they looked for new tools themselves and used them even though their teachers did not offer them the specific tool.

For the third phase results - the development of scaffolds - we selected the course of biomedical engineering because in it the support of different technological resources was a more important element in the design of the course. Firstly, we will present some of the observations made during the workshops in which students and teachers attempted to negotiate and adjust their learning scenario. In general, the students did not propose many ideas related to digital tools and TEL principles. However, the students found some problems in the teacher's design that were discussed, although the teacher did not apply the suggestions in the design.

Below are some examples of the discussions that observers noted during the co-design process:

Workshop 9:

- They do not set any proposals, but they discuss some of the design problems. They do not apply any changes (E.g.: In minute 50, Xavier's answer was about self-regulated learning).

- Changing some options is taken into account. It seems that video use can be positive for both students and teachers.

(E.g.: In minute 2:36:15, we have:

- Student: "That could be clearer".

- Teacher: "Yes, we can exemplify it with video".)

After seeing some of the discussions recorded during the workshops, we focused, as we noted, on the biomedical case. We must bear in mind that the aim of the biomedical course was to obtain clinical information exchange between heterogeneous systems of healthcare information.

Once the co-design process was completed, the teachers decided to organize the knowledge into several specialized health organizations; therefore, students were distributed into different groups. Each group was assigned a domain of knowledge that they had to work in.

Figure 3 shows the virtual campus where teachers distributed the different fields of knowledge to the groups. We can see that there were seven groups, each with its own knowledge area. Also, we can appreciate how the teachers developed new tools suggested by their students, such as wikis to create virtual spaces where students could 


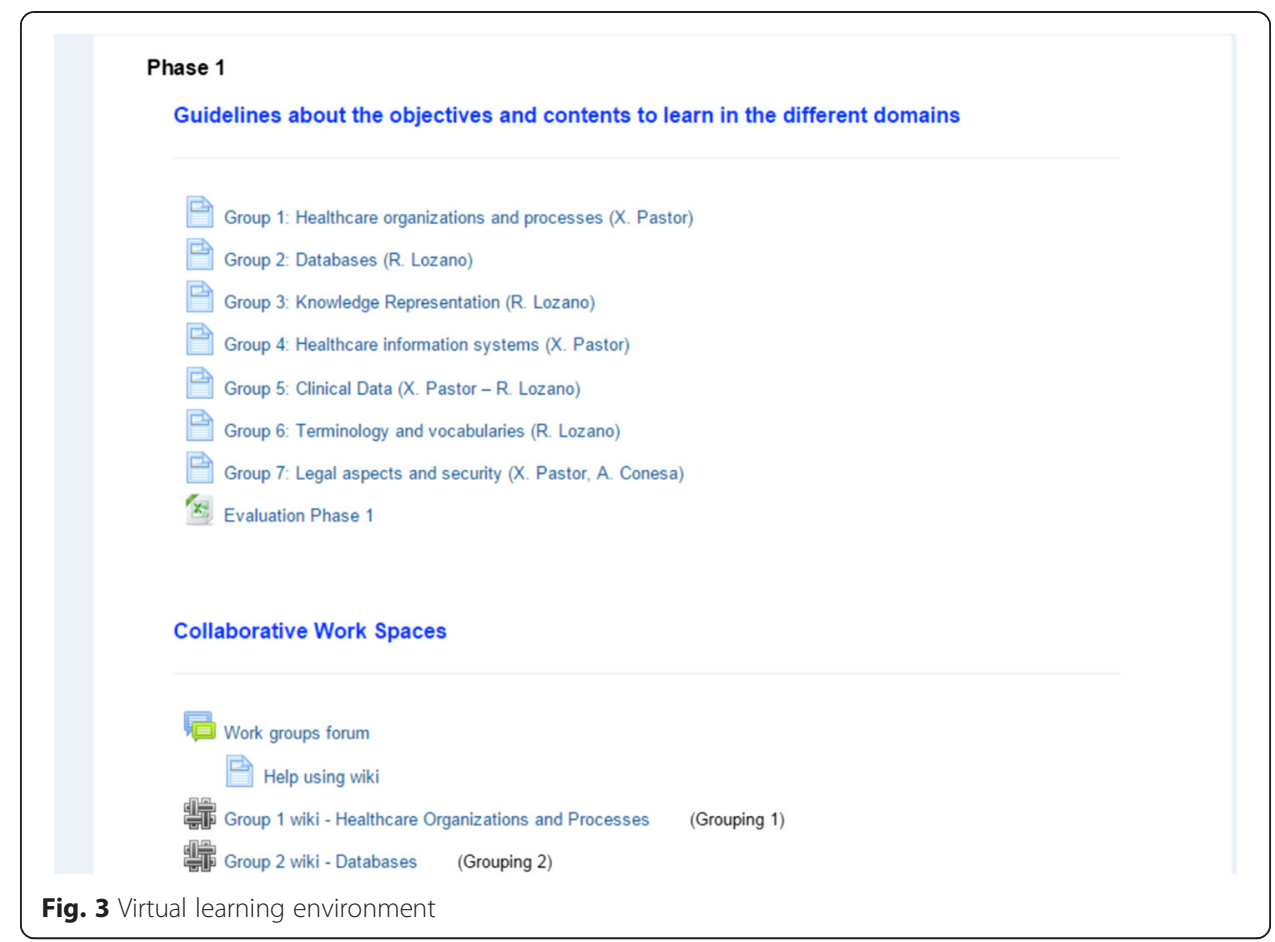

interact and build knowledge. Besides the use of wikis, students were free to collaborate using different tools (Fig. 4).

During the course, the students collaborated and communicated using tools as Facebook groups. Although the teachers had not anticipated this use, the students considered that this platform facilitated interaction better than the forum in the virtual campus.

\section{Students' and teachers' perception}

Once the co-design process was finished and the scenario was implemented, by means of a questionnaire (range 1-5 in Likert scale) we asked the 11 students about different parts of the process and implementation. The aim of the questions was to analyse their opinion of the learning process and the role of the teacher and students.

All students thought that the co-design process was a successful experience, and $100 \%$ of them would repeat it if they had the opportunity. The following graphic shows the students' opinion of co-design (0 is not satisfied and 5 totally satisfied) (Fig. 5):

Focusing on technology-enhanced learning, we asked the students if they had identified any new potential educational uses of ICT (item B3), and they marked this item with 3.5 out of 5 . This would indicate that the students did not learn any new educational uses of ICT during the workshops, however, as we will see, they did report a great deal of knowledge related with ICT in the workshops.

We then asked them (Fig. 6) to which areas they felt they had contributed most, and they mentioned selecting resources and learning tools (6 out of 6 ), together with choice of working methods. 


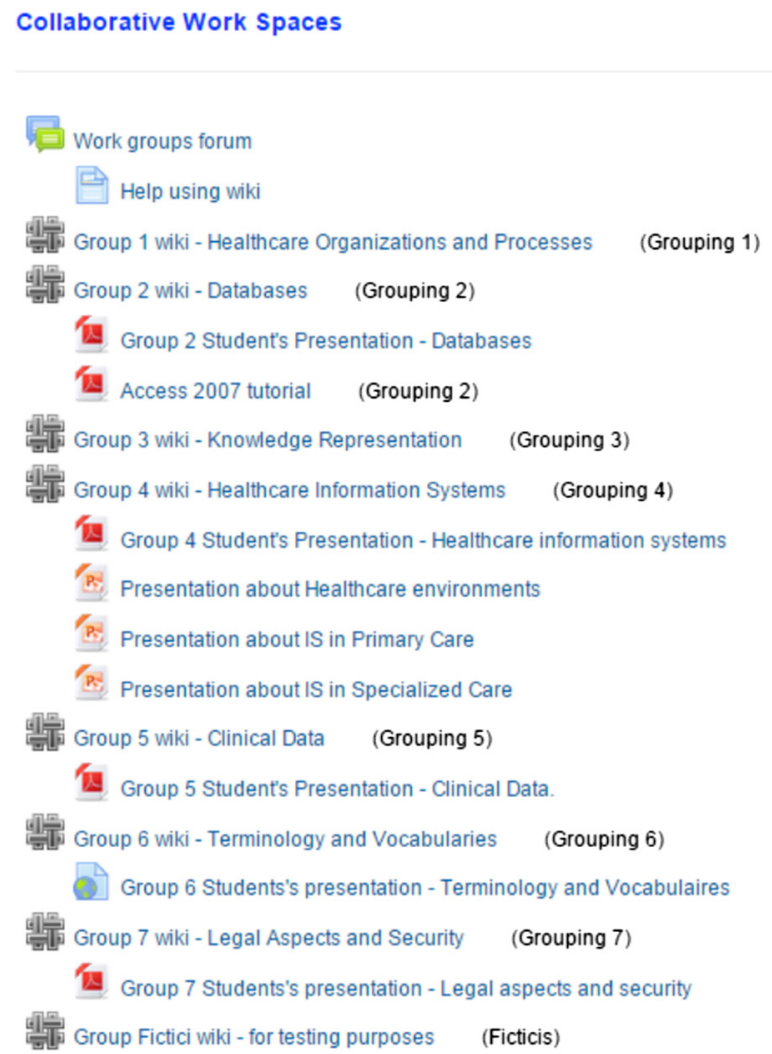

Fig. 4 Collaborative work spaces in the virtual learning environment

Therefore, the students reflected that they had contributed a lot to the design context with their ICT uses and experience, but they did not feel that they had learned any new potential educational uses of digital technology. In contrast to the students, the teachers did not feel they had worked very much on the concept of TEL principles.

In general, all highly regarded aspects are related with communication and collaboration between students and teacher. In the open questions, the students indicated that doing autonomous activities increased their learning and made them feel more involved:

"Working on part of the content in a group and explaining it to my colleagues has made me understand the content more clearly. I think it is because if you have to explain something you need to perfectly understand what you are going to present."

However, there were two items that the students considered they did not develop enough during the scenario: they felt they did not work in depth on some parts of the research work structure: Formulation of research questions and contrasting data.

After the course, the students viewed the teacher as a guide of their learning, not just as a person who transmits content. Moreover, they reported that working with the 


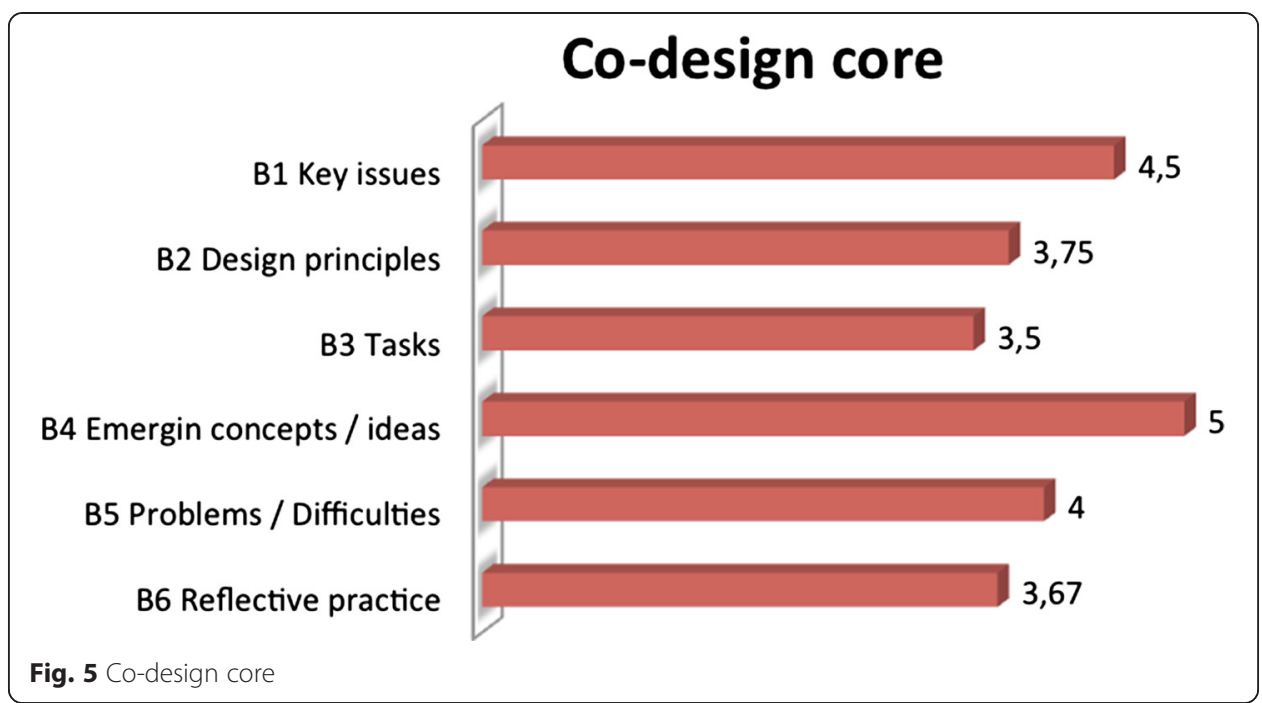

teacher to design the activities and learning scenarios enhanced their feeling of responsibility for managing their own learning.

The students' opinion of their own role tallies with the teacher's opinion. The students felt that their main function was to actively participate in the proposed activities and inquire into the specific topic they were working on. As a result, they considered that they had taken greater control of their own learning process during the entire scenario.

\section{Discussion and conclusion}

The Ecology of Resources Design Framework was identified by the participants as a good facilitator of the co-design process as it helped to identify the main resources for the different scenarios and encouraged dialogue and cooperation among the participants. The

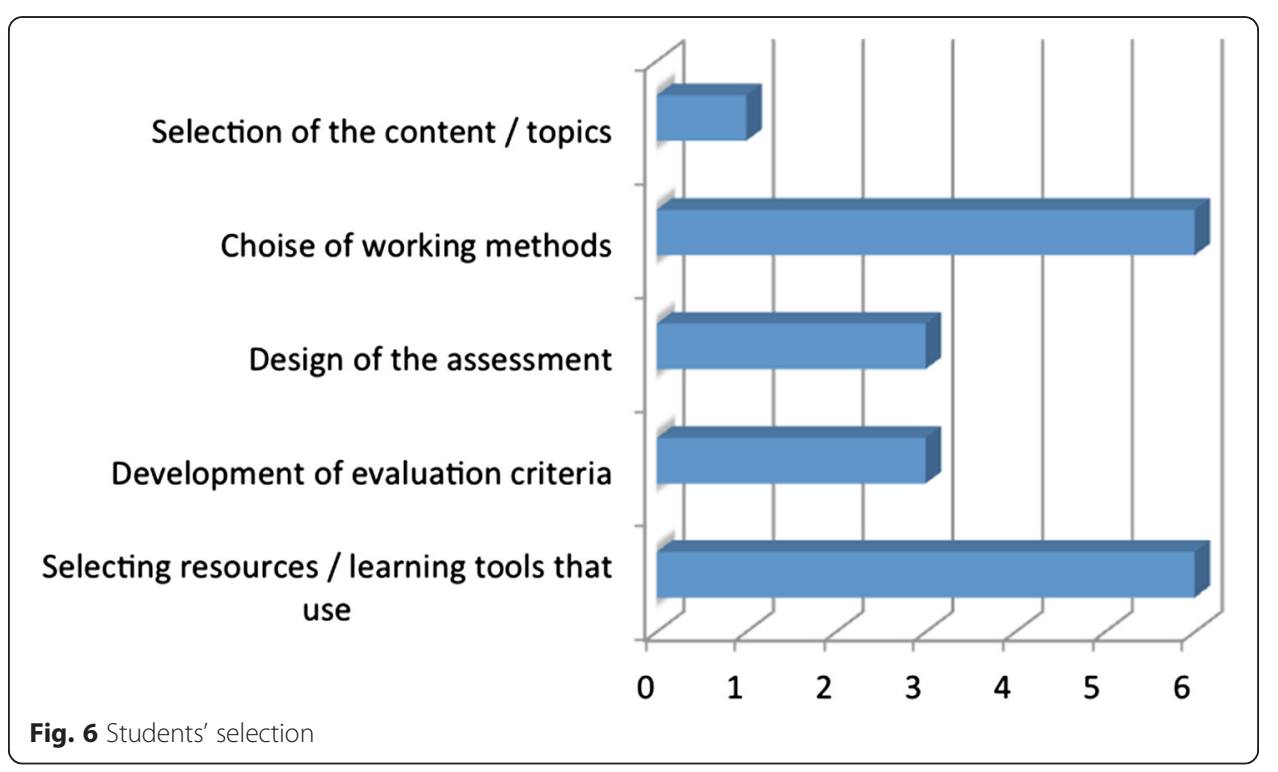


students felt particularly confident about their contribution related with the use of technology. In contrast, the teachers felt rather constrained because the use of the technology was limited to the virtual campus.

The categorization of different ICT tools was useful to establish a distinction among the different roles of the resources during the learning process. For instance, students from the UOC identified many more technologies (Masterclass, Skype meetings, videoconferences, etc.) to support online communication with the teachers.

The interaction between more able partners offering appropriate assistance to less able learners was complementary. The students provided more extensive resources during the co-design process but they did not have experience of using all the digital resources for learning purposes. For instance, students were more skilled at finding ICT tools for communication than were the teachers. However, the biomedical engineering teachers had explicit knowledge of databases and specific software in the area. This is coherent with studies that emphasize the need to establish a stronger connection between living and learning technologies (Kennedy, Judd, Churchward, Gray, \& Krause, 2008).

The Ecology of Resources model helps to support this ostensibly more democratic learning approach. This activity involves developing new educational theories that can encompass situations where the balance between learners and teachers is constantly changing. The type of learning relationship that we discussed at the outset when we considered the ZPD, ZAA and ZPA is one in which activity between a learner and a more able partner has been described during the co-design process. We now face a situation in which the teachers know more than the learners about the content of the course but may well not know as much as learners about the technologies that could act as learning tools. For this reason, we consider that there is now an important opportunity for reciprocal teaching and learning.

Another important goal of the study was to analyse the levels of intervention negotiated, assigned and managed during the co-design process with teachers and students. During the workshops, students and teachers maintained a good level of collaboration. Both agreed on the interest of confronting each other's perspectives: the students claim to have understood the complexity of teaching and learning design, the number of factors that need to be taken into account and the difficulty of satisfying both the teacher and the student view. However, in some situations when the students expressed a different opinion to the teachers, the latter tried to persuade them to adopt a traditional role.

Time seems to be a critical factor in co-design. A sustained dialogue over time is required to create the context of trust needed between students and teachers to allow them to express their ideas clearly. It also takes time and external facilitation for students to come to understand and use certain pedagogical concepts (Bovill, Morss, \& Bulley, 2009).

Our results show that from the students' point of view the distribution of responsibilities in the learning process must be continuously negotiated and decided by teachers and learners.

Involving students in learning design processes is a complex task because it implies profound changes in how to approach teaching and learning in higher education. However, we consider it very important in order to design learning scenarios that are more authentic, contextualized and meaningful to today's students. 
In summary, we have shown the positive implications of adopting co-design processes in terms of changing roles and relationships between teachers and students. Applying the Ecology of Resources model helps to support this process and provides a framework for analysing the complexity of the learning design. Supporting an ecology of learning resources must be a key consideration in the design of technology-rich learning activities that may lead to robust co-design processes.

\section{Authors' information}

Begoña Gros received the PhD degree in Pedagogy at the University of Barcelona in 1987. She was Vice-rector of Research and Innovation at the Open University of Catalunya (2007-2012), and currently she holds the academic position of professor at the University of Barcelona. She is the director of the research group Environments and materials for learning (EMA). Her research activities are in the area of the use of ICT in education, e-learning, digital games for learning, learning design and innovation.

Marta López Degree in Education, Master Teaching and Learning in Digital Environments at the University of Barcelona and University of London.

She also is a lecturer at the Faculty of Education at the UB, subjects related with communication technology and education. Her research lines are related to both formal and informal with ICT support university education and learning.

\section{Acknowledgments}

This work was supported by MCOC - Ministerio de Economia y Competitividad (EDU2012-37537).

Received: 18 November 2015 Accepted: 20 May 2016

Published online: 19 September 2016

\section{References}

Bovill, C., Cook-Sather, A., \& Felten, P. (2011). Students as co-creators of teaching approaches, course design, and curricula: implications for academic developers. International Journal for Academic Development, 16(2), 133-145.

Bovill, C., Morss, K., \& Bulley, C. J. (2009). Should students participate in curriculum design? Discussion arising from a first year curriculum design project and a literature review. Pedagogic Research in Maximising Education, 3(2), 17-26.

Clark, W., Logan, K., Luckin, R., Mee, A., \& Oliver, M. (2009). Beyond Web 2.0: mapping the technology landscapes of young learners. Journal of Computer Assisted Learning, 25(1), 56-69.

Conole, G., Creanor, L., Irving, A., \& Paluch, S. (2007). In their own words: Exploring the learner's perspective on e-learning. London: JISC. Available at: http://www.jisc.ac.uk/media/documents/programmes/ elearningpedagogy/iowfinal.pdf

Healey, M. (2014). Students as partners in learning and teaching in higher education. In Workshop Presented at University College Cork (Vol. 12, p. 15).

Kennedy, G. E., Judd, T. S., Churchward, A., Gray, K., \& Krause, K. L. (2008). First year students' experiences with technology: Are they really digital natives. Australasian Journal of Educational Technology, 24(1), 108-122.

Luckin, R. (2010). Re-designing learning context: Technology-rich, learner-centred ecologies. London: Routledge.

Luckin, R. (2006). Understanding learning contexts as ecologies of resources: From the zone of proximal development to learner generated contexts. In World Conference on E-Learning in Corporate, Government, Healthcare, and Higher Education (Vol. 2006, No. 1, pp. 2195-2202).

Luckin, R. (2008). The learner centric ecology of resources: a framework for using technology to scaffold learning. Computers \& Education, 50(2), 449-462.

Luckin, R., \& Du Boulay, B. (1999). Ecolab: The development and evaluation of a Vygotskian design framework. International Journal of Artificial Intelligence in Education, 10(2), 198-220.

Palaigeorgiou, G., Triantafyllakos, G., \& Tsinakos, A. (2011). What if undergraduate students designed their own web learning environment? Exploring students' web 2.0 mentality through participatory design. Journal of Computer Assisted Learning, 27(2), 146-159.

Sanoff, H. (2007). Special issue on participatory design. Design Studies, 28(3), 213-215.

Seale, J. (2009). Doing student voice work in higher education: an exploration of the value of participatory methods. British Educational Research Journal, 36(6), 995-1015.

Vygotsky, L. S. (1978). Mind in society: the development of higher psychological processes. Cambridge: Harvard University Press.

Wood, D., Bruner, J., \& Ross, G. (1976). The role of tutoring in problem solving. Journal of Child Psychology and Psychiatry, and Allied Disciplines, 17, 89-100.

Wright, S. (2012). Deep Learning Isn't about Technology. In http://plpnetwork.com/2012/09/24/deeper-learningtechnology/, access: 05.04.2015 